\title{
Patient satisfaction with radioiodine treatment and telephone follow-up for the management of thyrotoxicosis
}

\author{
Waiel A Bashari \\ Rebecca L Coates \\ Shahbaz Nazir \\ Naomi E Riddel \\ Oluwaseyi O Lawanson \\ Ahmed M Mohamed \\ Samson O Oyibo
}

Department of Diabetes and Endocrinology, Peterborough City

Hospital, Peterborough, UK
Correspondence: Samson O Oyibo

Department of Diabetes and Endocrinology, Peterborough City Hospital, Bretton Gate, Peterborough PE3 9GZ, UK

Tel +44 I733678000

Fax +44I733676787

Email samoyibo@yahoo.co.uk
This article was published in the following Dove Press journal:

Patient Preference and Adherence

13 May 2015

Number of times this article has been viewed

Background and objective: Patient satisfaction is of paramount importance when delivering a patient-centered service. Our hospital has been a center for the use of radioiodine to treat thyrotoxicosis for several years, but we began carrying out patient satisfaction surveys and implementing changes after 2008. The aim of the project reported here was to assess patient satisfaction with our radioiodine treatment and telephone follow-up service, and to compare results with our previous surveys.

Patients and methods: Anonymous patient satisfaction questionnaires were sent to all patients who received radioiodine treatment for thyrotoxicosis between January 2012 and December 2013. Patients were asked to answer four questions concerning informed consenting, treatment, and telephone follow-up using a four-point Likert scale, and post back the questionnaires. A suggestion box was included for comments and suggestions for improvement.

Results: A total of 56 questionnaires were posted out (to 44 females and 12 males) and 34 questionnaires were returned (60.8\% response rate). Between $94 \%$ and $100 \%$ of the responders, depending on the question asked, were satisfied with the service they received. Patients also put useful comments and suggestions in the suggestion box provided.

Conclusion: Patients with thyrotoxicosis were satisfied with our radioiodine treatment and telephone follow-up service. This survey has revealed areas for service improvement, and highlights the importance of patient satisfaction when assessing a patient-centered service.

Keywords: service improvement, patient-centered service, patient satisfaction survey, informed consenting

\section{Introduction \\ Thyrotoxicosis}

Thyrotoxicosis is a hypermetabolic condition due to overactivity of thyroid gland. In the UK the prevalence is about $2.0 \%$ in women and about $0.2 \%$ in men. ${ }^{1}$ Patients with thyrotoxicosis usually present to their general practitioner (family doctor) who then refers them to an endocrinologist for specialist care, during which time a management plan is formulated. After informed discussion, patients are commenced on an antithyroid drug (usually carbimazole) and asked to have regular blood tests to assess improvement. Medical treatment with antithyroid drugs can take up to 12-18 months and the condition can relapse after treatment in $50 \%$ of cases. If medical therapy fails then surgical removal of the thyroid gland or radioiodine ablation of the thyroid gland is the definitive treatment of choice. ${ }^{2}$ 


\section{Radioiodine treatment}

Radioiodine treatment has been used for benign thyroid disease for more than 60 years. ${ }^{3}$ This treatment takes advantage of the ability of the thyroid gland to take up iodine for thyroid hormone synthesis. The ${ }^{131} \mathrm{I}$ isotope-labeled iodine destroys the gland such that $80 \%-90 \%$ of patients become euthyroid within 8 weeks of receiving a single dose. ${ }^{4}$ Most of these patients will become hypothyroid thereafter and require life-long thyroxine replacement therapy.

\section{Our previous satisfaction surveys}

Peterborough City Hospital has been a center for radioiodine treatment for thyrotoxicosis for several years, but the service was transferred from an oncologist-supervised service to an endocrinologist-supervised service in 2008, and the telephone follow-up service was added during that period. Soon after that we began carrying out patient satisfaction surveys with the aim of assessing and improving patient experience with our service. No previously published or validated patient satisfaction questionnaire (PSQ) was found available to assess patient satisfaction with a radioiodine treatment and telephone follow-up service, so we devised our own PSQ. There were four questions, which covered four main domains: (1) patient satisfaction with the discussion and informed consenting procedure before receiving treatment, (2) satisfaction with the treatment process on the day of radioiodine treatment, (3) satisfaction with the post-treatment telephone follow-up service, and (4) satisfaction with the overall service. Each question required a response on a fourpoint Likert scale ("Strongly agree", "Agree", "Disagree", and "Strongly disagree"). A box was also provided on the PSQ for comments and suggestions for improvement.

During our previous surveys of 2009 and 2011 the PSQ was posted to patients who had radioiodine treatment during the periods 2008-2009 and 2010-2011, respectively. Results indicated that $89 \%$ and $94 \%$ of patients were satisfied with the overall service in the 2009 and 2011 surveys, respectively. We made improvements concerning informed consenting, experience on the treatment day, and calling patients to inform them of their blood test results and management changes. We also put all patients who had radioiodine treatment on a recall register so that follow-up calls could be made in a timely fashion, even if the patient forgot to call us first. ${ }^{5}$

\section{Importance of this satisfaction survey}

Radioiodine treatment for thyrotoxicosis can be scary for some patients and the introduction of a telephone follow-up service (telemedicine) is a new phenomenon for this group of patients. It is important that patients are given the opportunity to give us feedback on the service they receive, not only to assess patient satisfaction but also to highlight areas for service improvement. ${ }^{6}$

Therefore, the aim of the study reported here was to assess patient satisfaction with our radioiodine treatment and telephone follow-up service, comparing results with our previous two surveys carried out in 2009 and 2011, so as to make improvements in service provision and patient satisfaction.

\section{Materials and methods Treatment pathway}

Patients of our center are seen by the endocrinologist for informed consenting, prescribing, and setting a date for radioiodine treatment. Patients are asked to stop any antithyroid medication a week before the radioiodine treatment. The treatment is given in our outpatient department on a Friday and the patient is given a pathology request form to have a blood test on a Friday in exactly 6 weeks. The patient then informs us of the test by telephone so that telephone follow-up can take place to discuss test results and further management. The patient is also given a "yellow card", which contains information that reminds the patients of all the radiation protection precautions, the radiation dosage given, and contact information for further advice. The telephone follow-up service after blood tests not only helps to avoid treatment delays, but also reduces the need for unnecessary clinic appointments. Our radioiodine treatment pathway is shown in Figure 1.

\section{Sample population}

We have an average of 30 patients a year for radioiodine treatment. The sample population consisted of patients who had received radioiodine treatment for thyrotoxicosis between the months of January 2012 and December 2013. The patient list was obtained from the Radioiodine Treatment Recall Register and patients' postal addresses were obtained from the Patient Administration System.

\section{Questionnaires and administration}

The PSQ devised in 2009 was posted to all patients from the sample population mentioned. The PSQ had no patient details, were completely anonymized, and were posted by an independent helper with a stamped, self-addressed envelope enclosed. The timeframe for the collection of returned questionnaires was $6-8$ weeks. The postal and collection method used for this survey was the same as that used for 
Patient information leaflet given to patients who have an indication for radioiodine treatment

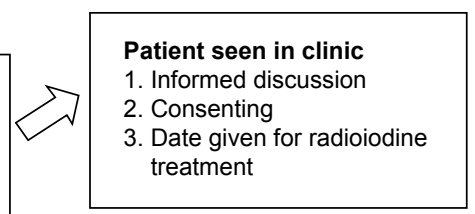

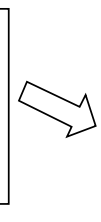

Radioiodine clinic

1. Concerns discussed

2. Treatment given

3. Yellow card given

4. Blood test request form for test in 6 weeks

5. Patient asked to call secretary 2 days after blood test

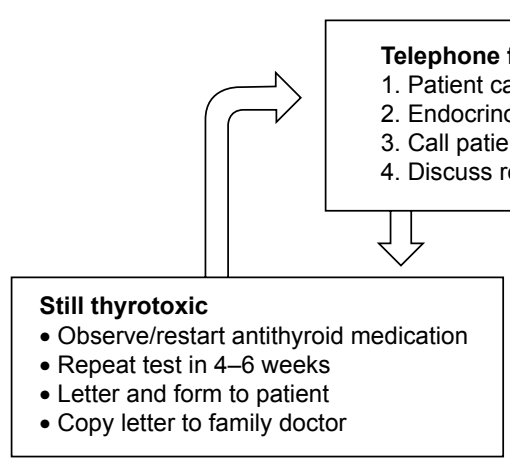

- Start levothyroxine

- Repeat test in 4-6 weeks

- Letter to patient and family doctor

Clinic letter to family doctor (copy to patient)

1. Detailing the above and precautions 2. With secretary's contact details

Figure I Patient pathway for radioiodine treatment and telephone follow-up.

our previous two surveys. The data obtained from this survey were analyzed both qualitatively and quantitatively.

This PSQ had already been assessed and passed by our Care Quality (Patient and Public Experience) department and had been used for the two previous surveys. As this survey was registered with our Quality, Governance and Compliance Department, ethical approval was not required before commencement.

\section{Results}

\section{Sample description}

A total of 56 patients had treatment over the 2-year study period. There were 44 females and 12 males with an average age of 57 years (range: 34-90). None of these patients had coexisting thyroid eye disease requiring concomitant steroid (prednisolone) therapy. Patients had a fixed dose of radioiodine (550 or $800 \mathrm{MBq})$.

\section{Response to questions}

The PSQs were posted out to all the 56 patients who had had radioiodine treatment over the 2-year period. Out of these, 34 completed questionnaires were returned $(60.8 \%$ response rate). Table 1 shows the four questions used in the PSQ along with corresponding results from the 34 responders. Overall, $94 \%-100 \%$ of responders, depending on the question asked, were satisfied (“Agree"/"Strongly agree") with the radioiodine treatment and telephone follow-up service. All responders (100\%) had a satisfying experience on the day of radioiodine treatment. Table 2 shows the number of satisfied ("Agree"/“Strongly agree”) responses to each question compared to the same results from our two previous patient satisfaction surveys done using the same questionnaires. The total numbers of satisfied responses to each survey (2009, 2011, and 2013) are also shown and indicate sustained patient satisfaction with our service.

Table I Questions used in the questionnaire with corresponding results from 34 responders

\begin{tabular}{|c|c|c|c|c|c|}
\hline \multirow{2}{*}{$\begin{array}{l}\text { Question } \\
\text { number }\end{array}$} & \multirow[t]{2}{*}{ Question } & \multicolumn{4}{|l|}{ Response, n (\%) } \\
\hline & & Strongly agree & Agree & Disagree & Strongly disagree \\
\hline I & $\begin{array}{l}\text { Do you feel you received adequate explanation about } \\
\text { radioiodine treatment before having the treatment? }\end{array}$ & $19(55.9)$ & |4 (4 I.2) & $0(0.0)$ & I (2.9) \\
\hline 2 & $\begin{array}{l}\text { Do you feel you had a satisfactory experience on the day of } \\
\text { receiving your treatment? }\end{array}$ & $24(70.6)$ & $10(29.4)$ & $0(0.0)$ & $0(0.0)$ \\
\hline 3 & $\begin{array}{l}\text { Concerning your blood test } 6 \text { weeks after treatment, } \\
\text { do you feel you had a prompt response from the doctor } \\
\text { regarding blood test results and further treatment? }\end{array}$ & $23(67.7)$ & $9(26.5)$ & $2(5.8)$ & $0(0.0)$ \\
\hline 4 & $\begin{array}{l}\text { Overall do you feel the care you received during and } \\
\text { shortly after radioiodine treatment was satisfactory? }\end{array}$ & $21(61.8)$ & $12(35.3)$ & $0(0.0)$ & I (2.9) \\
\hline
\end{tabular}


Table 2 A comparison of the number of satisfied ("Agree"/ "Strongly agree") responses over three consecutive patient satisfaction surveys

\begin{tabular}{llll}
\hline Survey statistic & \multicolumn{3}{l}{ Survey year } \\
\cline { 2 - 4 } & $\mathbf{2 0 0 9}$ & $\mathbf{2 0}$ I I & $\mathbf{2 0 ~ I 3 ~}$ \\
\hline Posted, n & 50 & 42 & 56 \\
Received, n & 28 & 3 I & 34 \\
Response rate, \% & 56 & 74 & 6 I \\
"Agree"/“Strongly agree” & & & \\
responses, n (\%) & & & \\
$\quad$ Question I & $27(96.4)$ & $31(100.0)$ & $33(97.1)$ \\
$\quad$ Question 2 & $27(96.4)$ & $30(96.8)$ & $34(100.0)$ \\
$\quad$ Question 3 & $23(82.1)$ & $30(96.8)$ & $32(94.1)$ \\
$\quad$ Question 4 & $25(89.3)$ & $29(93.6)$ & $33(97.1)$ \\
$\quad$ Total for each survey* & $102(91.1)$ & $120(96.8)$ & $132(97.1)$ \\
\hline
\end{tabular}

Note: *Total number of satisfied ("Agree"/"Strongly agree") responses for each survey.

Two patients were not satisfied ("Disagree"/"Strongly disagree") with the post-treatment telephone follow-up service, indicating that the service concerning discussing the 6-week blood test result and management changes thereof needed improvement. One patient was not pleased with the overall service, in particular the point about not receiving adequate explanation during informed consenting about a post-treatment side effect (this patient also left a comment).

\section{Comments and suggestions}

A total of 17 responders $(50 \%)$ made useful comments and further suggestions for improvement of the radioiodine treatment and telephone follow-up service. The comments and suggestions are shown in Figure 2.

\section{Comments indicating areas for improvement}

One responder commented on the fact that, during the interview, there was no warning given about the possible return of symptoms between when the antithyroid medication is stopped and when the radioiodine treatment will begin to work. The other responder was unhappy with the overall service because of severe muscle pain after treatment. This responder also wrote a letter saying that if she had known about the possibility of this side effect, she would not have volunteered to have the radioiodine treatment. Another responder commented on the fact that there was no information concerning the complete handover of care to their usual family doctor once the radioiodine treatment had worked and long-term levothyroxine replacement had been started. Another responder gave us the impression that the communication of results and management plans to patients' family doctors needed improvement.

- No improvement needed for this treatment, as I was followed closely at each stage.

- I was dealt with promptly also to which I am thankful. Many thanks.

- I found the endocrinologist to be a pleasant man who explained everything clearly. A real gentleman.

- I cannot fault any of my treatment[,] everything was explained to me gently, also cannot fault the treatment I had while in hospital before my treatment, many thanks for the endocrinologist and his team.

- I received such wonderful care and kindness for which I give my grateful thanks.

- No comments.

- Thank you very much, everything is fine.

- Felt supported at all times. Excellent care, thank you.

- Very satisfied with treatment. Well done.

- Keep up the excellent work.

- My own doctors questioned blood tests and seem to be not "up to speed" with my treatment.

- Possible warning of enhanced symptoms of over-activity with the interval between stopping medication and satisfactory action of the radioactive iodine could be helpful.

- None.

- Due to the long gaps between tests, thyroid patients spend long period without support. This worry is increased by what appears to be a complete handover to the GP after radioiodine treatment. Would have helped to have known this in advance.

- Promptness of follow-up calls much appreciated.

- I received excellent care; suggestion for improvement would be hard to find; many thanks.

- Very dissatisfied with the treatment side effects. Would not recommend this treatment to anybody.

Figure 2 Comments and suggestions for improvement made by responders for improving the radioiodine treatment and telephone follow-up service. Abbreviation: GP, general practitioner. 


\section{Comments indicating satisfaction}

Eleven responders made comments indicating that they were satisfied with the service as a whole. Another two responders indicated "No comment" in the box provided.

\section{Discussion}

Patient satisfaction is of paramount importance when delivering a patient-centered service. We assessed patient satisfaction with the service provided and compared the results with those of our two previous surveys done in 2009 and 2011. Results of this survey indicate that there is sustained patient satisfaction with our radioiodine treatment and telephone follow-up service.

\section{Implications to our service}

The results of this survey have provided us with valuable quantitative and qualitative information, which has helped us to improve our service in relation to patients needs. First, it became apparent that we needed to improve the 6-week telephone follow-up call service. This is a crucial time for patients who need to know if the radioiodine treatment has worked and whether they can start taking life-long thyroxine replacement therapy or need another blood test at a later date. As previously mentioned patients did their blood test on a Friday and informed us the Monday after, resulting in a 3-4-day delay before getting a callback and another 1-2-day delay if they needed new medication. In light of this we have changed the 6-week blood test from the Friday to the Monday of that same week, so that patients can get a call from the endocrinologist within 24-48 hours of having their blood test. Hopefully this will improve patient satisfaction with the post-treatment telephone follow-up service.

Secondly, in response to the comments concerning inadequate provision of pretreatment information, we have now mentioned in the patient information sheet the possibility of symptoms from post-treatment hypothyroidism occurring prior to or in between blood tests.

Thirdly, because antithyroid drugs are stopped a week before treatment and not restarted after treatment, we have mentioned in the patient information sheet the possibility of an exacerbation of symptoms of thyrotoxicosis and the possible need for symptomatic treatment during the waiting period.

Lastly, we have included a statement to remind patients that they will be followed up by their family physician once the radioiodine has worked and they have started long-term levothyroxine, but patients can still call the endocrinologist for advice.

\section{Possible reasons for high satisfaction}

Results from our three surveys demonstrate high satisfaction rates with the radioiodine treatment and telephone follow-up service. All patients are provided with up-to-date information concerning radioiodine and given contact details of the health care provider that does the informed consenting, gives the treatment, and does the telephone follow-up calls. Additionally, patients are able to have their treatment on a date convenient to them. Patients are also made aware of the treatment pathway or service flow. All these factors could be contributory to the high satisfaction rates observed. Further patient satisfaction surveys, which include follow-up oneto-one interviews (face-to-face or telephone) with all the patients would be useful in elucidating possible contributory factors to maintaining the high patient satisfaction rates with our service.

\section{Previous studies in this field}

Obtaining patients' perspective on disease and its management through satisfaction surveys is important when delivering patient-centered care. ${ }^{7}$ As far as we are aware, there are no published data looking at patient satisfaction with a radioiodine treatment and telephone follow-up service, from informed consenting to the post-treatment telephone follow-up phase. A previous survey concentrating on radioiodine treatment demonstrated that $96 \%$ of patients were satisfied with radioiodine treatment for thyrotoxicosis. ${ }^{8}$ A more recent survey concentrating on just telephone follow-up for thyroid function test results also indicated a similar satisfaction rate. ${ }^{9}$ This current survey is the first, as far as we are aware, to have looked at patient satisfaction with the combination of a radioiodine treatment and telephone follow-up service.

\section{Study limitations}

This study has its limitations. Firstly, there was a response rate of $60.8 \%$, which is similar to that reported in other mail surveys. ${ }^{10,11}$ Nonetheless, it would have been useful to know the characteristics (eg, age, social class, etc) of the nonresponders versus the responders so as to ascertain possible reasons for the nonresponse. The questionnaires were anonymous so we could not interview nonresponders and responders to assess the extent of any nonresponse bias present in this study. Secondly, we could not perform follow-up calls or send follow-up letters to remind those patients who did not respond. Follow-up calls or letters would probably have improved the response rate. Thirdly, because of the small sample size we could not assess for any statistical 
significance concerning the numerical improvement in the satisfaction scores over the three surveys. Additionally, because of the small sample size the findings may not be generalized to other health care centers. Finally, the period between receiving radioiodine treatment and then receiving the PSQ would be significantly different for each patient, and this variable could have influenced individual responses to the questions. Therefore, a prospective design with a larger sample size would greatly enhance the qualitative and quantitative power of a future survey.

\section{Conclusion}

This patient satisfaction survey has demonstrated that patients are satisfied with our radioiodine treatment and telephone follow-up service for the management of their thyrotoxicosis. This survey has also demonstrated areas for service improvement, which should be the aim when using patient satisfaction surveys to assess patient-centered care. We hope to repeat this patient satisfaction survey in 2 years.

\section{Author contributions}

All seven authors - WAB, RC, SN, NER, OOL, AMM, and SOO - made substantial contributions to the conception and design of the study, acquisition of data, analysis and interpretation of data; contributed to drafting and revising the article; gave final approval of the version to be published; and are in agreement to be accountable for all aspects of the work in ensuring that questions related to the accuracy or integrity of any part of the work are appropriately investigated and resolved.

\section{Disclosure}

The authors report no conflicts of interest in this work.

\section{References}

1. Vanderpump MP, Tunbridge WM, French JM, et al. The incidence of thyroid disorders in the community: a twenty-year follow-up of the Whickham Survey. Clin Endocrinol (Oxf). 1995;43(1):55-68.

2. Bahn RS, Burch HB, Cooper DS, et al; American Thyroid Association; American Association of Clinical Endocrinologists. Hyperthyroidism and other causes of thyrotoxicosis: management guidelines of the American Thyroid Association and American Association of Clinical Endocrinologists. Thyroid. 2011;21(6):593-646.

3. Franklyn JA. The management of hyperthyroidism. NEngl J Med. 1994; 330(24):1731-1738.

4. Holm LE, Lundell G, Dahlqvist I, Israelsson A. Cure rate after 131I therapy for hyperthyroidism. Acta Radiol Oncol. 1981;20(3):161-166.

5. Volkova E, Janakiraman G, Oyibo SO. Radioiodine treatment for thyrotoxicosis in a district hospital: an audit and patient satisfaction survey. Endocrine Abstracts. 2012;28:P377.

6. Ilioudi S, Lazakidou A, Tsironi M. Importance of patient satisfaction measurement and electronic surveys: methodology and potential benefits. International Journal of Health Research and Innovation. 2013;1(1):67-87.

7. Cleary PD. The increasing importance of patient surveys. Now that sound methods exist, patient surveys can facilitate improvement. $B M J$. 1999;319(7212):720-721.

8. Bhattacharyya A, Parthiban A, Tymms DJ. Radioactive iodine for hyperthyroidism: patient satisfaction survey. Clin Endocrinol (Oxf). 2000; 52(6):795-796.

9. Davies C, Vas P, Oyibo SO. Telephone follow-up for the management of thyrotoxicosis: a patient satisfaction survey. J Telemed Telecare. 2013;19(1):29-32.

10. Asch DA, Jedrziewski MK, Christakis NA. Response rates to mail surveys published in medical journals. J Clin Epidemiol. 1997;50(10): 1129-1136.

11. Cummings SM, Savitz LA, Konrad TR. Reported response rates to mailed physician questionnaires. Health Serv Res. 2001;35(6):1347-1355.
Patient Preference and Adherence

\section{Publish your work in this journal}

Patient Preference and Adherence is an international, peer-reviewed, open access journal that focuses on the growing importance of patient preference and adherence throughout the therapeutic continuum. Patient satisfaction, acceptability, quality of life, compliance, persistence and their role in developing new therapeutic modalities and compounds to optimize

\section{Dovepress}

clinical outcomes for existing disease states are major areas of interest for the journal. This journal has been accepted for indexing on PubMed Central. The manuscript management system is completely online and includes a very quick and fair peer-review system, which is all easy to use. Visit http://www. dovepress.com/testimonials.php to read real quotes from published authors. 